\title{
As configurações subjetivas de docência e suas transformações no decorrer da trajetória profissional
}

The subjective configurations of teaching and its transformations in the course of the professional trajectory

\author{
Marciléa Serrão Resque ${ }^{1}$ \\ José Moysés Alves ${ }^{2}$
}

\section{Resumo}

Apresentamos, no presente artigo, um recorte de uma pesquisa de doutorado, na qual objetivamos compreender as configurações subjetivas de docência e suas transformações no decorrer da trajetória profissional de um professor de ciências e biologia. Analisamos as informações a partir da perspectiva histórico-cultural da Teoria da Subjetividade de González Rey. Apoiados na epistemologia qualitativa, apresentamos um estudo de caso, organizado a partir das informações construídas por meio de complemento de frases, questionário aberto e entrevista individual. Os resultados apontam que diferentes configurações de sentidos subjetivos de docência são produzidas no decorrer o percurso profissional e estas estão profundamente enlaçadas às suas interações sociais, nos diferentes contextos em que o professor transitou, desde a infância. O referencial adotado possibilitou dar visibilidade ao sujeito concreto, em sua trajetória singular, o que costuma ser desconsiderado nas generalizações que resultam de uma abordagem do percurso docente por ciclos.

Palavras chave: Trajetória profissional docente, Configurações subjetivas, Teoria da Subjetividade.

\section{Abstract}

In this article, we present a review of a doctoral research, in which we aim to understand the subjective configurations of teaching and its transformations during the professional career of a professor of science and biology. Based on the historical-cultural perspective of González Rey's Theory of Subjectivity. Based on qualitative epistemology, we present a case study, organized from the information constructed through phrases complement, open questionnaire and individual interview. The results show that different configurations of subjective senses of teaching are produced along the professional path and these are deeply linked to their social interactions, in the different contexts in which the teacher has transited since childhood. The adopted framework allowed to give visibility to the concrete

\footnotetext{
${ }^{1}$ Escola EFM Tenente Rêgo Barros | serraomarcilea@gmail.com

2 Universidade Federal do Pará | jmalves@ufpa.br
} 
subject, in its singular trajectory, which is usually disregarded in the generalizations that result from an approach of the teaching path by cycles.

Key words: Subjective configuration, Professional trajectory, Subjectivity senses, Subjectivity.

\section{Introdução}

As discussões presentes neste artigo são provenientes de uma pesquisa realizada sobre a trajetória profissional de professores de ciências e biologia, tendo como principal enfoque teórico a Teoria da Subjetividade de Fernando González Rey (2003; 2007; 2017). Com esta perspectiva, buscamos compreender as diferentes configurações subjetivas sobre a docência que são produzidas pelos professores em diferentes momentos em que se dedicam ao magistério. Elegemos como foco principal, a compreensão das mudanças nas configurações subjetivas sobre a docência, em diferentes momentos do percurso profissional.

Os estudos sobre a trajetória profissional docente correspondem a um campo muito presente na literatura, sendo considerado como espaço de interseção de temas importantes da área da educação. Nesta perspectiva, a carreira docente têm sido tradicionalmente compreendida como "um percurso que tem em vista a promoção e o desenvolvimento profissional através do exercício de uma profissão ao longo de um dilatado período de tempo" (FAUSTINO, 2011, p. 14).

Como conceito social e historicamente construído, as pesquisas sobre a carreira dos professores têm sido desenvolvidas amparadas por diferentes perspectivas teóricas, que acabam produzindo modos de compreensão acerca do tempo de atuação na profissão. Encontramos estudos que concentravam suas análises na dimensão profissional, tradicionalmente compreendida a partir da realidade dos contextos de formação e atuação dos professores. As trajetórias profissionais eram então, frequentemente, associadas às diferentes fases ou ciclos do desenvolvimento humano (TOLFO, 2002), as quais consideravam que os docentes atravessavam períodos ou etapas características na profissão e partilhavam entre si, muitos aspectos em comum. As discussões presentes nestas pesquisas, predominantemente relacionavam o percurso profissional ao universo das escolas e do desenvolvimento de competências consideradas como específicas do magistério.

De outro modo, as pesquisas fundamentadas nas histórias de vida e narrativas autobiográficas colocaram em foco outras esferas da vida docente. Suscitaram novos exercícios teóricos ao reconhecer a dimensão pessoal como aspecto constituinte e portanto, relevante para ser incluída nos estudos sobre a carreira dos professores (CHAVES, 2013). Estas pesquisas apresentavam análises que iam além das salas de aulas, da escola e dos processos de formação profissional. Nelas, as temáticas como emoções, afetos, valores e 
histórias pessoais que frequentemente passavam ao largo nas leituras dos percursos docentes, passaram a compor as análises das narrativas sobre as trajetórias dos professores.

Para Souza (2011) estas narrativas demarcaram outros modos de percepção dos processos de formação e vida docente na pesquisa educacional, que se diferenciavam das abordagens tradicionais centradas nos aspectos profissionais da docência. Nóvoa (2009, p. 212) ao sublinhar enfaticamente que "o professor é a pessoa, e que a pessoa é o professor" e mais ainda que "é impossível separar as dimensões pessoais e profissionais", corrobora com a visão da docência como campo complexo em que os campos pessoal e profissional estão profundamente e inextrincavelmente emaranhados.

No entanto, ainda que exista consenso sobre a importância da abordagem de outras perspectivas da vida docente nas pesquisas sobre a carreira profissional, o entendimento da dimensão subjetiva aparece ainda, predominantemente, relacionado "às especificidades e individualidades do professor" (OLIVEIRA; TACCA, 2016, p. 19), como campo pertencente à esfera particular, que teria pouca ou mesmo nenhuma relação com seu universo profissional, compreendida de forma desvinculada dos contextos históricos, sociais e culturais de sua produção.

As pesquisas que abordavam a temática subjetividade transitavam com maior familiaridade no campo da psicologia. Predominantemente associada à ideia de consciência para se referir ao que era interno e particular de cada pessoa, o conceito de subjetividade era frequentemente usado para representar atributos da psique humana (GONZÁLEZ REY, 2005; TACCA, 2017). As distâncias estabelecidas entre sujeito, cenários históricos e sociais foram então ressaltadas em diferentes concepções ao longo da história da psicologia, contribuindo para produzir dicotomias entre sujeito e meio, interno e externo, passado e presente.

A Teoria da Subjetividade, fundamentada na psicologia histórico- cultural, se contrapõe à construção da subjetividade como algo eminentemente interno e invariável. Na perspectiva de González Rey (2007), este conceito aparece como representação qualitativa da psique, que se (re)constrói dinamicamente nas diferentes relações, espaços e tempos que os indivíduos vivenciam. Para Neubern (2004), na compreensão defendida pela teoria, a subjetividade apresenta caráter integrador de dimensões comumente entendidas de forma dicotomizada.

Partindo dessas considerações, compreendemos que analisar a trajetória profissional docente a partir do enfoque da Teoria da Subjetividade traz importantes contribuições para o entendimento deste percurso desenvolvido pelos professores ao longo de sua profissão como caminho complexo e multirreferenciado, relacionado a outras dimensões de suas vidas.

Na perspectiva teórica assumida, entendemos que a subjetividade se organiza e se constitui por meio do diálogo incessante entre os sujeitos, sua historicidade e meio social. Essa relação dialética entre os cenários individuais e sociais oferece possibilidades para 
pensar a constituição da subjetividade dos professores a partir de simultaneidades e embates da experiência docente ao longo de suas trajetórias pessoais e profissionais, para além dos espaços de formação profissional e atuação docente. À vista destas questões, passamos a considerar que as vivências e histórias de vida singulares dos professores, se entrelaçam e se expressam em suas trajetórias profissionais.

A docência passa a ser entendida como constructo dinâmico e complexo, que se configura e se articula nos diferentes campos e momentos da vida dos professores. As situações vivenciadas na família, no trabalho, na escola, contextos sociais, assim como, a visão de mundo, de conhecimento e de si mesmo, transitam e convergem na história dos sujeitos como qualidades inerentes de suas vivências na carreira docente (SCOZ, 2012).

A teoria apresenta categorias nucleares, desenvolvidas para "gerar visibilidade aos processos e formas de organização da subjetividade" (GONZÁLEZ REY; MITJÁNS MARTINEZ, 2017, p. 62), dentre elas estão os sentidos subjetivos e configurações subjetivas. Tais categorias nos auxiliaram a pensar sobre as diferentes produções subjetivas de docência que acontecem ao longo da carreira dos professores. A categoria sentido subjetivo é considerada como unidade elementar para o estudo da subjetividade, ao integrar, de modo sistêmico, as produções simbólicos- emocionais que emergem no curso das experiências dos sujeitos. As configurações subjetivas, corresponderiam à organizações sistêmicas e flexíveis de sentidos subjetivos produzidos pelos sujeitos nos diferentes tempos e espaços de sua vida pessoal e profissional e que estão em permanente mobilidade. São constructos que permitem compreender os estados subjetivos dominantes da questão estudada (GONZÁLEZ REY; MITJÁNS MARTINEZ, 2017).

González Rey assinala que se abre uma nova "zona de sentido" na construção do pensamento psicológico sobre a subjetividade, que não se refere à mera internalização do que vem de fora do sujeito e aparece dentro dele (GONZÁLEZ REY, 2005).

O sujeito não é reflexo, tampouco um epifenômeno de outros processos, mas representa uma instância de ruptura geradora, capaz de assumir opções diferentes diante da situação em que vive. Esse sujeito, sem dúvida, está subjetivamente constituído (GONZÁLEZ REY, 2003, p. 37).

Tendo em vista as ideias de sentido subjetivo, configuração subjetiva e trajetória docente, entendemos que ao longo dos anos de exercício docente, ensinando e aprendendo no universo das salas de aulas e de outros espaços sociais, os professores movem-se entre sentidos e significados que estão em permanente tensão e mobilidade no campo da docência.

Deste modo, buscamos compreender como se configura subjetivamente a docência para um professor de ciências e biologia em diferentes momentos de sua carreira profissional. 


\section{Método}

A pesquisa foi desenvolvida a partir da abordagem qualitativa, orientada pelos pressupostos da Epistemologia Qualitativa de González Rey (2017). Esta compreensão apresenta como fundamentos principais, a valorização do processo de construção e interpretação das informações, o reconhecimento do caso singular como instância legítima de produção do conhecimento e a comunicação e o diálogo como processo permanente e fundamental para a produção das informações de pesquisa.

Para o estudo da trajetória docente, participou um professor licenciado pleno em ciências biológicas que atuava em uma escola pública federal da cidade de Belém do Pará. $\mathrm{Na}$ intenção de preservar sua identidade, passaremos a chamá-lo pelo nome fictício de Bruno.

Na pesquisa desenvolvida foram usados diferentes instrumentos para a produção das informações, como questionários abertos, complemento de frases, entrevistas individuais e conversas informais. Com vistas ao referencial assumido, os instrumentos de pesquisa são entendidos como ferramentas interativas e não vias geradoras de resultados capazes de refletir a realidade. Assim, tais recursos atuaram como dispositivos indutores que permitiram a livre expressão do professor Bruno, possibilitando sua expressão de forma diferenciada e emocionalmente envolvida.

O questionário aberto era composto por três frases amplas que deveriam ser complementadas. As frases eram: Na época em que decidi ser professor, Hoje sou um professor, Minha vida pessoal e profissional. Após o envio dos questionários abertos e sua leitura atenta, algumas questões sobre a trajetória percorrida pelo professor Bruno começaram a despontar. Na tentativa de compor um sistema de informações sobre o percurso profissional do sujeito da pesquisa, utilizamos um complemento de frases para produção das informações. Tal instrumento era composto de 52 frases que deveriam ser complementadas pelo docente e abrangiam diferentes questões sobre seu percurso pessoal e profissional, assim como, as relacionadas aos projetos, sonhos, sentimentos, experiências e expectativas pessoais dos docentes.

Além do questionário aberto e do complemento de frases, também foi realizada uma entrevista com o professor Bruno, na qual utilizamos um roteiro previamente elaborado que, em linhas gerais, abordava sua história de vida pessoal e profissional. Ademais, promovemos conversas informais sobre estas mesmas temáticas. Para González Rey (2002), a legitimação dos instrumentos de pesquisa está associada à sua intenção de valorizar a expressão do sujeito.

Com as informações produzidas no curso da pesquisa, levantamos indicadores que nos permitiram gerar significados em relação as diferentes expressões dos professores acerca de suas trajetórias docentes. O confronto com indicadores produzidos pelos diversos instrumentos, nos permitiram produzir hipóteses, as quais fundamentaram as discussões 
presentes neste texto e a proposição do modelo teórico sobre as mudanças que aconteceram nas configurações subjetivas dos professores envolvidos no estudo.

Inspirados nas pesquisas de Cavaco (1999), optamos por um método de análise da trajetória docente denominado de transversal, que corresponderia a cortes temporais do percurso docente, os quais permitiriam "aprofundamento situacional" e seriam "facilitadores da produção de sentido nas narrativas" (CAVACO, 1999, p. 161). Diante de tais considerações, destacamos três momentos principais da trajetória profissional contada pelo professor participante, que são: 1) As opções pela docência, 2) A entrada na carreira docente e os anos iniciais e o 3) $O$ momento atual.

Para compor a análise, tomamos como base as diferentes expressões do participante, apresentadas em trechos das informações obtidas a partir dos instrumentos usados, complemento de frases (CF), entrevistas (EN), conversas informais (CI) e questionário aberto (QA).

A seguir apresentamos a produção dos pesquisadores sobre a trajetória profissional do professor Bruno a partir da leitura teórica da Teoria da Subjetividade.

\section{Resultados e discussões}

\section{O caso do professor Bruno}

O professor Bruno é natural do estado do Paraná, juntamente com sua família, migrou de sua terra natal para a zona rural do estado do Mato Grosso, durante a expansão das lavouras de soja naquele Estado. Em nossas conversas informais, sempre destacou que "era um homem do interior, acostumado com o árduo trabalho no campo e com fortes valores e referências familiares" (EN).

Na época em que a pesquisa foi realizada, havia quatro anos que ele residia na cidade de Belém do Pará, em virtude da aprovação em concurso público para o quadro docente do Ministério da Defesa, para professor de ciências e biologia em uma escola de ensino fundamental e médio. No decorrer da entrevista, nos contou que tinha 15 anos de formação docente e mestrado na área de ciências ambientais, e ainda que, em decorrência da falta de professores nas escolas do interior em que trabalhou, já lecionou disciplinas para as quais não tinha formação acadêmica, como História, Geografia e Ensino Religioso. Atualmente Bruno é professor de ciências no ensino fundamental II.

Para o professor Bruno, a carreira docente foi um dos únicos caminhos profissionais possíveis, tendo em vista suas condições reais de morador de uma pequena cidade do interior do Brasil. Sobre esse momento da profissão, Bruno comentou que sua opção foi consequência da "falta de alternativas profissionais" (QA), pois a Licenciatura em Ciências Biológicas era um dos poucos cursos que era oferecido pela universidade na cidade mais próxima em que ele morava (EN). 


\section{O movimento da subjetividade no decorrer da trajetória profissional docente}

\section{Elementos subjetivos envolvidos no momento de escolha da profissão docente}

A análise interpretativa da trajetória do professor Bruno possibilitou a construção da configuração subjetiva deste momento de opção pela docência. Consideramos que dois sentidos subjetivos principais figuravam nesta etapa de sua docência, sinalizando o curso da experiência vivida. São eles: a) Docência como construção afetiva e desenvolvimento profissional e b) Docência em ciências e biologia relacionada à formação cidadã e educação científica.

Em relação ao sentido subjetivo que relacionava a docência como construção afetiva e desenvolvimento profissional, o professor expressou dimensões tanto individuais quanto sociais que constituíram seu momento de escolha pela carreira docente, como seu projeto pessoal de fazer um curso universitário; sua vontade de seguir um caminho profissional diferente daquele de seus pais; a expectativa de seus familiares quanto a ascensão social que um curso de nível superior poderia proporcionar a ele ; a falta de condições objetivas para cursar veterinária ou zootecnia; a construção de novos projetos profissionais que incluíam a docência em ciências e biologia.

Ainda que para Bruno a opção pela docência tenha sido, de algum modo, circunstancial, seu processo de escolha pela licenciatura em Ciências Biológicas não se limitou apenas às questões relacionadas ao momento da decisão em seguir o curso universitário ofertado em sua cidade. Por ocasião da entrevista, quando perguntamos ao professor se havia ficado triste ou mesmo contrariado em ter que cursar uma graduação diferente daquelas planejadas, ele respondeu que "Não! Pelo contrário, foi uma oportunidade de continuar a estudar... comecei a pensar em outras possibilidades" (EN).

Bruno se posicionou de forma ativa diante das diferentes esferas que compuseram este momento de escolha pela carreira. Configurou e mobilizou sentidos subjetivos positivos em relação à profissão docente provenientes de outros espaços e tempos, relacionados à sua satisfação em conseguir ingressar em uma universidade, a percepção do orgulho que seus familiares sentiam em relação à sua decisão em prosseguir os estudos e às perspectivas profissionais em fazer pós graduação na área ambiental.

Em relação a constituição do sentido subjetivo de docência em ciências e biologia relacionada à formação cidadã e educação científica, o lugar em que o professor ocupava naquele momento de escolha pela docência, como agricultor que almejava fazer curso superior, que possuía muitos conhecimentos sobre o cultivo de vegetais e manejo de animais, morador de uma pequena cidade do interior que apresentava graves problemas ambientais, relacionados à expansão das lavouras de soja e milho e a destruição de grandes áreas de mata, expressaram-se nos sentidos subjetivos produzidos por ele nesta etapa de sua trajetória como professor. 
Bruno manifestou que em seu processo de escolha pela carreira docente, a possibilidade de 'dar voz' a essas temáticas importantes, vivenciadas em seu contexto social, foram para ele elementos motivadores,

Comecei a pensar que como professor de biologia poderia mudar a realidade em que vivia (EN).

Conhecia muito sobre a vida no campo, como cuidar de plantas e animais (EN).

Queria ser professor para... mudar a realidade que vivia (CF),

Na minha cidade essas questões (ambientais) eram muito problemáticas.

Atingia a todos de uma certa maneira! (EN).

Nesta direção, os sentidos produzidos expuseram a perspectiva complexa de tais construções subjetivas. Em meio às pretensões pessoais e familiares e diante das possibilidades de escolhas profissionais, o professor Bruno projetou modos singulares de compreender a profissão que iam além do reconhecimento das barreiras sociais de desvalorização e da ausência de condições para cursar a graduação que planejara. Configurou para si sentidos subjetivos que passaram a relacionar a docência em ciências e biologias à oportunidade de agenciar os conhecimentos que possuía sobre o cultivo de vegetais e a criação animais em suas aulas. Bruno projetava ser professor de ciências e biologia para fomentar debates e atitudes, com os quais os alunos pudessem se posicionar em relação às problemáticas ambientais da região em que moravam.

\section{Elementos subjetivos envolvidos no momento de entrada e primeiros anos da carreira docente do professor Bruno}

Bruno iniciou suas atividades docentes em sua própria cidade. Trabalhava em escolas públicas e em virtude da 'carência de professores, passou a assumir também as disciplinas de História e Ensino religioso.

Consideramos dois sentidos subjetivos principais neste momento de seu percurso profissional: a) Docência como responsabilidade com o outro e comprometida com seu lugar social e b) Docência: desencantos e a construção de novas perspectivas profissionais.

Em relação ao sentido de docência como responsabilidade com o outro e comprometida com seu lugar social, para Bruno, a motivação em ser professor de ciências e biologia, tinha aportes no reconhecimento da docência como atividade que poderia influir de forma positiva na formação cidadã dos alunos e na melhoria da vida das pessoas de sua região. Este sentido era nuclear em sua configuração subjetiva de docência e integrava de forma dinâmica, elementos sociais e individuais, profundamente relacionados à sua história pessoal (SCOZ, 2009).

Nas escolas em que o professor iniciou a carreira, a maioria dos estudantes era da zona rural, e assim como ele, compartilhavam além de vivências e conhecimentos, situações ambientais problemáticas, como o uso de agrotóxicos e contaminação do solo e da água 
da região por estes produtos. Acreditava que ao incluir estas discussões em suas aulas, ele "contribuiria para a formação dos alunos" (QA), compreendia que os conhecimentos científicos "somente tem razão se for pro aluno entender sua realidade" (QA). Arroyo (2009, p. 110) argumenta que "o como somos docentes condiciona nossa docência tanto ou mais do que os conteúdos que ensinamos". Bruno almejava impactos maiores com sua docência do que a comunicação dos saberes disciplinares, expressou que "sempre quis... que meus alunos fossem felizes" (CF), "queria contribuir com a vida deles" (QA).

Em relação ao sentido de docência: desencantos e a construção de novas perspectivas profissionais, o professor Bruno comentou sobre os muitos desafios que teve que enfrentar neste momento de sua carreira profissional. O receio de falhar, de "não dar conta" (CI) das muitas responsabilidades que estavam envolvidas em sua atividade pedagógica, foram para ele uma temática central e recorrente nesta etapa da vida docente. No entanto, compreendemos que tal receio não estava relacionado somente às questões que envolviam condições concretas de seu trabalho, como o conteúdo da disciplina ou questões relativas à sala de aula propriamente dita, mas estava associado, sobretudo, ao sentimento de não conseguir ser o professor que ele havia projetado.

Ao falar sobre sua trajetória, Bruno comentou que por diversas vezes cogitou abandonar a profissão nestes momentos iniciais. Expressou que se sentia insatisfeito com o pouco envolvimento do corpo docente e administrativo com as situações escolares, "via o modo em que as pessoas tratavam os alunos, com indiferença, a falta de compromisso com seu trabalho e com a educação me incomodava e entristecia, não queria ser assim também" (EN).

O professor Bruno expressou de forma emotiva, o sentimento vivido nos anos iniciais de sua docência, para um professor que se auto descrevia como "muito sonhador e idealista" (EN), a entrada na carreira docente foi desafiadora. Um tempo que, para Cavaco (1999), circulam instabilidades, incertezas e desafios.

O projeto pessoal de construir sua docência comprometida com a formação cidadã dos alunos, respeitando seus conhecimentos e modos de vida, esbarrou em muitas dimensões do contexto educativo, que afetaram, sobremaneira, suas expectativas e projetos.

A tensão entre a subjetividade individual e social foi marcante neste momento da trajetória, geradora de conflitos que colocou o professor diante do desafio de continuar a acreditar em seus princípios e projetos em meio a uma realidade complexa, que envolviam muitos outros sujeitos: docentes, administradores e alunos. Tal vivência repercutiu na motivação de Bruno e o levou a abandonar a docência e seguir outros caminhos profissionais.

\section{Elementos subjetivos envolvidos no momento atual da carreira docente do professor Bruno}


Após cinco anos atuando como consultor ambiental, o retorno à docência acabou acontecendo quando o professor foi aprovado em um concurso público e retomou seus caminhos profissionais em outra cidade e em outro cenário educativo bastante diferente daquele vivenciado em seus anos iniciais.

Foram muitas mudanças pelas quais ele passou, tanto no plano pessoal quanto em relação à sua carreira profissional. Mudou-se para uma grande metrópole, separou-se de seus familiares, afastou-se pela primeira vez da rotina e das atividades do campo, começou a trabalhar em uma grande escola, que tinha estruturas organizacionais e materiais muito diferentes daquelas que tinha experimentado em seus primeiros anos na profissão docente.

Muitos elementos compuseram este reencontro com a 'vontade de ser professor' na trajetória profissional de Bruno. Restringi-los apenas às questões estruturais de seu novo cenário educativo, seria, no entanto desvalorizar o caráter dialético da constituição dos sujeitos (MOTTA; URT, 2009). Para González Rey.

A ideia de sujeito recupera o caráter dialético e complexo do homem, de um homem que de forma simultânea representa uma singularidade e um ser social, relação esta que não é de determinação externa, mas uma relação recursiva em que cada um está simultaneamente implicado na configuração plurideterminada dentro da qual se manifesta a ação do outro (González Rey, 2003, p. 224).

Tendo como perspectiva estes encaminhamentos teóricos, em que a compreensão da formação do sujeito se dá a partir da relação indivisível entre este e o meio social. As expressões subjetivas são, portanto, construções do professor Bruno, tendo em vistas o que ele viveu e experimentou em seu novo espaço social e, sob esta ótica, não podem ser situadas como simples reflexo de uma realidade objetiva.

Desta forma, compreendemos que dois sentidos nucleares compunham a configuração subjetiva do professor Bruno, a) Docência partilhada em ciências e biologia: como um caminho desejável e b) Docência como serviço ao outro, exercício ético e solidário.

Em relação ao primeiro sentido, docência partilhada em ciências e biologia: como um caminho desejável, ele expressa que

Hoje sou um professor que acredita no ofício, na sociedade e que somos parte do universo. Sou um professor que sente o "frio no estômago" ao iniciar uma aula. Satisfação e sensação de "missão cumprida" ao final do dia (EN).

As expressões afetivas presentes nesta entrevista apontam para a configuração de sentidos subjetivos construídos pelo professor. Em seu momento atual, Bruno manifestou que ao reformular seus sonhos e compor novas expectativas de vida, passou a acreditar na profissão como um caminho profissional possível. 
O caso do professor Bruno ressalta as singularidades das histórias de vida profissional quando analisadas à luz da Teoria da Subjetividade. Muitas dimensões apontadas por outras pesquisas (CAVACO, 1999; XAVIER, 2014) estiveram presentes também na carreira do professor, como o impacto do isolamento profissional, a falta de condições financeiras, o desencanto e o descrédito que sentiu em relação à profissão. Contudo, ao se reportar a estas questões, o professor Bruno se colocava em perspectiva, em diálogo com os diferentes cenários sociais do qual fez parte e o quanto ele afetou e foi afetado por tais vivências. González Rey (2011, p. 136) argumenta que não é apenas o sujeito individual está constituído pela subjetividade social, mas ele também "é um dos momentos constituintes daquela".

A permanente tensão entre o que ele desejava ser/ fazer como professor de ciências e biologia marcou sua trajetória profissional, para além das fases ou ciclos de vida docente estabelecidos. Os eventos e as emoções foram simultâneos e tiveram diferentes origens e repercussões em sua vida. Quando perguntei quem era o professor Bruno atualmente? Ele me respondeu "alguém muito feliz e satisfeito" (EN). O sentimento atual era de contentamento, mesmo diante de questões que em outros tempos tiveram um impacto maior em sua subjetividade, como a pouca valorização social da docência. O professor esclarece que, em grande medida, considera que esta mudança aconteceu em virtude do que experimentou em seu novo contexto profissional, espaço em que pôde resgatar seus projetos pedagógicos e exercitar colaborativamente e afetivamente sua profissão.

\footnotetext{
Aqui [referindo-se a atual escola] tenho tempo de estudar, conversar com meus colegas, me preparo para as aulas, vejo os meus colegas se esforçando para fazer um bom trabalho. Tem dificuldades, claro, mas mesmo assim temos vontade de trabalhar. (EN).
}

Em relação ao sentido subjetivo de docência como serviço ao 'outro', exercício ético e solidário. Para Bruno, a docência não estava desvinculada de seus valores pessoais. 0 serviço, a dedicação e o compromisso com o outro eram questões centrais em seu exercício profissional. Em vista a estas questões, considerava que a sensibilidade, dedicação e a atenção aos processos de ensino e aprendizagem eram fundamentais, "ensinar ganha sentido ... quando nos esforçamos para que os alunos aprendam mais do que conhecimentos" (CF).

Para Contreras (2002), a perspectiva moral do processo de ensino assumida pelos professores, estaria diretamente relacionada com a dimensão emocional inerente à qualquer relação educativa. Para este autor, "sentir-se compromissado ou 'obrigado' moralmente reflete este aspecto emocional na vivência das vinculações com o que se considera valioso" (CONTRERAS, 2002, p. 77).

No caso do professor Bruno o sentido de docência como serviço ao 'outro', foi produzido a partir dos diferentes tecidos relacionais e contextuais. Em outro momento, 
quando se definiu como um 'homem do interior' (EN), ele não se referia apenas à sua condição geográfica, mas ao que ele valorizava e acreditava como pessoa. Este sentido subjetivo constituía um dos núcleos de sua configuração no momento atual da carreira profissional.

No marco da Teoria da Subjetividade, "as emoções caracterizam o estado do sujeito ante qualquer ação" (GONZÁLEZ REY, 2003, p. 242). São qualificadas como produção cultural e subjetiva, presentes, portanto, em todas as dimensões e atividades desenvolvidas pelos sujeitos. Essa compreensão permite avançar no entendimento da emoção como registro eminentemente biológico, fortuito e pontual, que pode ou não estar presente em determinadas situações. A docência como produção subjetiva, relaciona de modo indissociável e complexo os pensamento e emoção na produção dos sentidos subjetivos.

O professor retoma questões importantes já anunciadas por ele em outros momentos de sua trajetória docente, no caso a valorização da docência como compromisso ético, generoso e socialmente responsável, "aprendi que na educação fluem discursos e esperanças, mas as atitudes as ações emanam de cada um de nós, diretamente envolvidos" (QA). Sobre estas questões, Tacca (2005, p.217) compreende que "o sujeito é participante ativo das diferentes configurações que assume, mas que guarda sempre uma unidade interna, correspondente à sua história de relações com os outros".

\section{O Movimento da subjetividade em relação à docência em diferentes momentos da trajetória profissional do professor Bruno}

Analisar a trajetória docente do professor Bruno, tendo como referência a Teoria da Subjetividade, é compreender que "o sujeito, assim, ao enfrentar o mundo vivido, o faz na dinâmica de uma configuração subjetiva, na qual aparece o mundo pelo qual se orienta" (TACCA; GONZÁLEZ REY, 2008, p. 146). Neste enfoque, as configurações subjetivas de docência expressaram, de modo singular, os enfrentamentos com o que foi vivido e significado simbólico e emocionalmente por Bruno nos seus quinze anos de profissão.

$\mathrm{Na}$ trajetória de Bruno, as tensões entre o que ele planejara ser como professor de ciências e biologia e a realidade de seu contexto profissional inicial, foram provocadores de mudanças em suas configurações subjetivas.

A relação complexa e ao mesmo tempo contraditória entre a subjetividade individual e a social, marcou os diferentes momentos do percurso docente de Bruno. Na etapa que se refere à escolha pela profissão, a falta de opção para cursar a graduação que havia planejado que, em tese poderia ser decepcionante para o professor, foi configurada por ele sob outras bases. Em meio às condições singulares de sua história de vida, Bruno reposicionou seus sonhos, expectativas pessoais e familiares. Desta forma, a licenciatura em Ciências Biológicas passou a representar tanto a oportunidade de alinhar suas vivências e conhecimentos como produtor rural, quanto seus sonhos de entrar na Universidade e poder contribuir, como professor, para a formação cidadã das pessoas que viviam na região em 
que morava. Essas questões estavam na base de sua motivação para a docência em ciências e biologia neste momento de sua carreira profissional.

O segundo momento foi particularmente emblemático e gerador de conflitos para o professor Bruno. A tensão estabelecida entre a sua subjetividade individual e a complexidade dos espaços sociais em que iniciou sua carreira profissional, foi produtora novas configurações de sentidos. O projeto pessoal de construir sua docência comprometida com a formação cidadã dos alunos, respeitando seus conhecimentos e modos de vida, esbarrou em muitas dimensões do contexto educativo, que afetaram, sobremaneira, suas expectativas e projetos. A relação com o outro, representado pelos demais membros da escola que não compartilhavam os mesmos ideais educativos, influenciaram a emergência de sentidos subjetivos relacionados ao descrédito e desencanto com a docência. Em face destas questões, Bruno procurou outros caminhos profissionais fora da licenciatura.

O terceiro momento da carreira docente foi para o professor Bruno tempo de muitas mudanças, tanto contextuais quanto de relacionamentos pessoais/ profissionais. Em um novo cenário educativo, redescobrir a docência como caminho de auto realização, foi para ele um movimento subjetivo de reconhecimento do outro como parceiro e colaborador.

\section{Considerações finais}

Ao final deste artigo, no qual apresentamos discussões teóricas acerca da construção da carreira docente e suas transformações na perspectiva da Teoria da Subjetividade, compreendemos, amparados em Rossato e Mitjáns Martinez (2013), que diferentes configurações subjetivas de docência foram produzidas pelo professor Bruno no decorrer da trajetória profissional.

No momento das opções pela docência, motivado pela necessidade de entrar no mercado de trabalho e diante de suas possibilidades de escolha profissionais, o professor produziu sentidos subjetivos que ultrapassaram as barreiras sociais de desvalorização da profissão. Para Bruno a docência figurou como possibilidade de entrada no nível superior e para isto, ele projetou metas para sua docência tomando por base suas experiências cotidianas.

Nos momentos que correspondem à entrada na carreira docente e os primeiros anos na profissão, o professor vivenciou situações que suscitaram a tomada de decisões importantes em relação a que professor de ciências e biologia ele queria ser. Os desafios da prática o fizeram posicionar-se diante da realidade educacional que vivia. Experimentou sentimentos conflituosos após cursar uma licenciatura e ingressar no mercado de trabalho. Motivado pela necessidade de melhorar suas condições materiais e de realizar-se profissionalmente, enfrentando os desafios da prática, o sujeito produziu sentidos subjetivos diretamente relacionados com sua prática docente e seu papel social. 
No momento atual de sua carreira docente, Bruno se sentia confortável e satisfeito com seu ambiente de trabalho. Motivado pelo desejo de aperfeiçoar sua prática docente e torná-la relevante para os alunos e para si mesmo, o sujeito produziu sentidos singulares que incluíram a partilha e a colaboração entre os pares como condição importante para o exercício da docência em ciências e biologia.

A docência como constructo subjetivo, passou por diferentes configurações. Tais mudanças impactaram o modo do professor Bruno ser/estar em sua docência ao longo da carreira profissional. Sentidos subjetivos de docência em ciências e biologia gerados na interface de sua subjetividade individual com a subjetividade social, estiveram na base de decisões tomadas pelo docente, em relação ao seu futuro profissional e à condução de sua carreira como professor de ciências e biologia.

Com vistas à base teórica adotada na pesquisa, as singularidades da história de vida profissional do professor Bruno foram realçadas para dar visibilidade aos elementos subjetivos que figuravam em diferentes etapas de sua carreira docente. A trajetória profissional compreendida a partir da Teoria da Subjetividade, amplia as possibilidades de análises da carreira profissional para além dos espaços formais de atuação ou mesmo de formação profissional. Aponta para a mobilidade e heterogeneidade destas construções subjetivas sobre a docência, que foram produzidas em diferentes tempos e espaços da vida dos docentes.

Com o desenvolvimento deste estudo, compreendemos que a subjetividade do professor Bruno se constituiu nos processos de produção e (re) configuração de sentidos subjetivos ao longo do tempo que se dedicou à sua profissão. Tais sentidos constituíram diferentes configurações subjetivas que dialogaram com os espaços sociais que ele vivenciou, integrando diferentes dimensões da sua vida, as experiências familiares, sua formação pessoal e profissional, os valores éticos e morais, suas concepções de educação.

Estudos sobre tais processos são importantes para compreender como os professores subjetivam sua docência no decorrer do tempo da carreira profissional. A mobilidade das configurações subjetivas apontam para os impactos que a relação dialética entre sujeitos e as condições históricas e sociais apresentam ao longo do tempo de suas carreiras profissionais. 


\section{Referências}

ARROYO, Miguel G. Ofício de mestre: imagens e autoimagens. 11 ed. Petrópolis. Rio de Janeiro: Vozes. 2009.

CAVACO, Maria Helena. Ofício do professor: o tempo e as mudanças. In: NÒVOA, Antônio (org.). Profissão professor. Porto- Portugal, Porto editora, 1999.

CHAVES, Silvia Nogueira. Reencantar a ciência, reinventar a docência. São Paulo: Editora Livraria da Física, 2013.

CONTRERAS, José. A autonomia de professores. São Paulo, Cortez editora, 2002.

FAUSTINO. Isabel Maria Lopes Ribeiro. Trajectorias de professionalidade e ciclo de vida profissional: Um contributo para o conhecimento dos professores de educação especial. 2011. 260 f. Dissertação (Mestrado em Ciências da Educação) - Escola Superior de Educação de Lisboa, Lisboa, 2011.

GONZALEZ REY, Fernando Luis. Sujeito e subjetividade: uma aproximação histórico-cultural. São Paulo: Thomson Learning, 2005. Revista Psicologia da Educação, São Paulo, 24, $1^{\circ}$ sem. de 2003.

GONZALEZ REY, Fernando Luis. Pesquisa Qualitativa e Subjetividade os processos de construção da informação. São Paulo: Thomson Learning, 2005.

GONZALEZ REY, Fernando Luis. As categorias de sentido, sentido pessoal e sentido subjetivo: sua evolução e diferenciação na teoria histórico-cultural. Revista Psicologia da Educação, n. ${ }^{\circ}$ 24, p. 155-179, $1^{\circ}$ semestre de 2007.

GONZALEZ REY, Fernando Luis. Subjetividade e saúde: superando a clínica da patologia. São Paulo: Cortez, 2011.

GONZALEZ REY, Fernando Luis; MITJÁNS MARTINEZ, Albertina. Subjetividade: teoria, epistemologia e método. Campinas - SP: Editora Alínea, 2017.

MOTA, Maria Alice Alves da, URT, Sonia da Cunha. Pensando o sujeito: um diálogo entre Castoriaids e González Rey. Psicologia em estudo, Maringá, v. 14, n. 4, p. 621-629, out./dez. 2009.

NEUBERN, Mauricio da Silva. Complexidade \& psicologia clínica: desafios epistemológicos. Brasília: editora Plano, 2004.

NÓVOA, Antonio. Para uma formação de professores construída dentro da profissão. Revista Educacion. Madrid, 2009.

OLIVEIRA, Luciana da Silva; TACCA, Maria Carmen V. R. Subjetividade, docência e ação formativa: o valor heurístico de uma nova base teórica. In: Ação formativa docente e práticas pedagógicas na escola. TACCA, Maria Carmen V. R. (Org.). Campinas, SP: Editora Alínea, 2016.

ROSSATO, Maristela; MARTíNEZ, Mitjáns Albertina. Desenvolvimento da subjetividade: análise de histórias de superação das dificuldades de aprendizagem. Revista Semestral da Associação Brasileira de Psicologia Escolar e Educacional, São Paulo. v. 17. n. 3. jul/dez de 2013. 
SCOZ, Beatriz. Aprendizagem e ensino de professores: sentidos subjetivos. In: MITJÁNS MARTINÉZ, Albertina. A Complexidade da Aprendizagem: destaque ao ensino superior. Campinas: Alínea, 2009.

SCOZ, Beatriz. Identidade e subjetividade de professores: sentido do aprender e do ensinar. São Paulo: Vozes, 2012.

SOUZA, Eliseu Clementino de. Memória, (auto) biografia e formação. In: CHAVES, Silvia Nogueira. BRITO, Maria dos Remédios de. Formação e Docência: perspectivas da pesquisa narrativa e autobiográfica (Org.). Belém, CEJUP, 2011.

TACCA, Maria Carmen. Relação Pedagógica e desenvolvimento da subjetividade. In: GONZÁLEZ REY. F. L (Org.). Subjetividade, Complexidade e Pesquisa em Psicologia. Rio de Janeiro: Thomson Learning, 2005.

TACCA, Maria Carmen. A pesquisa como suporte da formação e ação docente. Campinas, São Paulo: Editora Alínea, 2017.

TACCA, Maria Carmen; GONZÁLEZ REY, Fernando. Produção de sentido subjetivo: as singularidades dos alunos no processo de aprender. Psicologia: ciência e profissão. Brasília, v. 28, n. 1, p. 138-161, 2008.

TOLFO, Suzana da Rosa. A carreira profissional e seus movimentos: revendo conceitos e formas de gestão em tempos de mudanças. Rev. Psicol., Organ. Trab., Florianópolis, v. 2, n. 2, p. 39-63, dez. 2002 . Disponível em <http://pepsic.bvsalud.org/scielo. >. Acesso em 11 jun. 2018.

XAVIER, Mírian. A Aprendizagem profissional da docência de professores de ciências e biologia. 2014, 322 f. Tese (Doutorado em Educação). Curso de pós- graduação em educação da Universidade Federal do Mato Grosso do Sul. Campo Grande, 2014. 